\title{
Liquidity and Market Efficiency in the World's Largest Carbon Market*
}

\author{
Gbenga Ibikunle \\ Corresponding Author \\ University of Edinburgh Business School \\ University of Edinburgh \\ 29 Buccleuch Place \\ Edinburgh, EH8 9JS \\ Gbenga.Ibikunle@ed.ac.uk \\ Tel: +44 (0) 1316515186 \\ Andros Gregoriou \\ Brighton Business School \\ Brighton University \\ Moulsecoomb, BN2 4AT \\ a.gregoriou@brighton.ac.uk
}

Andreas G. F. Hoepner

ICMA Centre, Henley Business School

University of Reading

Reading, RG6 6BA

a.hoepner@icmacentre.ac.uk

\author{
Mark Rhodes \\ Hull University Business School \\ University of Hull \\ Hull, HU6 7RX \\ m.rhodes@hull.ac.uk
}

\footnotetext{
* We thank ICE Data LLP for the provision of the dataset used in this study. We are grateful to participants at the $10^{\text {th }}$ Academic Conference of the British Institute of Energy Economics Conference at the University of Oxford's St John's College, the Accounting and Finance Seminar Series at the University of Edinburgh and the Finance Seminar Series at the University of East Anglia. We also thank Jo Danbolt, George Daskalakis, Bill Rees, Seth Armitage, Raphael Markellos and Ivan Diaz-Rainey for helpful comments and discussions. All remaining errors are our own.
} 


\title{
Liquidity and Market Efficiency in the World's Largest Carbon Market
}

\begin{abstract}
We investigate liquidity and market efficiency on the world's largest carbon exchange, IntercontinentalExchange Inc.'s European Climate Exchange (ECX), by using intraday shorthorizon return predictability as an inverse indicator of market efficiency. We find a strong relationship between liquidity and market efficiency such that when spreads narrow, return predictability diminishes. This is more pronounced for the highest trading carbon futures and during periods of low liquidity. Since the start of trading in Phase II of the EU Emissions Trading Scheme (EU-ETS) prices have continuously moved nearer to unity with efficient, random walk benchmarks, and this improves from year to year. Overall, our findings suggest that trading quality in the EU-ETS has improved markedly and matures over the 2008-2011 compliance years.
\end{abstract}

\section{JEL Classifications: G12, G13, G14, G15, G18}

Keywords: Liquidity; Order flow; Market efficiency; Return predictability; European Climate Exchange; EU Emissions Trading Scheme (EU-ETS); Carbon futures

\section{Introduction}

The EU Emissions Trading Scheme (EU-ETS) is both the largest compulsory cap and trade scheme in the world and the most potent regional climate change policy tool arising from the EU's 2002 ratification of the Kyoto protocol, a global treaty on greenhouse gas emission reduction. ${ }^{1}$ The operation and success of the EU-ETS will significantly inform the direction of global climate policy, identifying effective mechanisms for carbon trading and the effect of different restrictions on the price of emissions. The scheme may also affect the growth of the emission-constrained economies in Europe, New Zealand, the United States, Japan and other parts of the world. This is because regulatory arbitrage is likely to be greater when carbon trading is limited to significantly smaller geographical locations, as is the case at this time. The market is artificial and dependent on environmental policy and regulation; it is therefore exposed to greater levels of uncertainty than is the case for most 'natural' commodities.

\footnotetext{
${ }^{1}$ At present there are at least 18 of such market-based schemes worldwide, and the EU-ETS is the largest of them all, driving more than $90 \%$ of all global transactions in carbon financial instruments (see Ibikunle et al., 2013).
} 
Emissions permits have to be surrendered on an annual basis. In principle, therefore, futures contracts on emissions permits offer significant benefits, both as instruments for hedging price risk and as mechanisms to assist in the smooth operation of the system as a whole. Understanding the microstructure of these markets therefore goes a long way in helping to inform global climate change policy. This paper contributes to an understanding of the market microstructure for an emerging market that addresses the climate change challenge.

Financial markets perform two key functions: the provision of liquidity, and price discovery (see O'Hara, 2003). The extent to which the price discovery process reflects all available information in the market can be described as an indication of the market's efficiency (see Fama, 1970). In regular financial markets liquidity plays an important role in enhancing price discovery and by extension, pricing efficiency. In this paper we first test whether this holds for the EU-ETS, and thus determine that intraday pricing efficiency is inextricably linked to daily liquidity. Specifically, we confirm that the predictability of intraday returns from intraday lagged order flows significantly decreases on days when the market enjoys greater liquidity. Fama's (1970) view of market efficiency implies the absence of return predictability, while market microstructure literature emphasises the reflection of private information in prices as a measure of market quality (see Chordia, Roll, and Subrahmanyam, 2008). Kyle (1985) notes that even the most efficient of markets reflects different levels of private information. Naturally, when markets attain higher levels of liquidity due to an exogenous event they may more easily absorb private information, since increased liquidity may encourage more informed trading due to a fall in transaction costs (see Admati and Pfleiderer, 1988). The link between liquidity and pricing efficiency is even more important in the case of the EU-ETS, where EU policies are being implemented in order to increase transactions in carbon permits. Such policies can be regarded as exogenous events akin to policy regarding tick size changes on NYSE, for example. In this paper, where we identify the commencement of compliance 
years as an exogenous event corresponding to the tightening of trading spreads (see Figure 2), a confirmation of the liquidity-return predictability link would imply that increased trading activity induced by EU policies could improve EU-ETS pricing efficiency. This is the first empirical study to directly examine the intraday evolution of this relationship in an environmental market like the EU-ETS. Secondly, we test whether market efficiency improves over the course of 40 months in Phase II of the EU-ETS, by using compliance years as exogenous regimes which correspond to reductions in trading spreads. The study thus presents the longest period study of intraday analysis of intraday pricing dynamics in the EU-ETS. Thirdly, we test whether intraday prices move closer to random walk benchmarks from compliance year to compliance year in Phase II. Deviations from a random walk benchmark would implicitly suggest higher levels of noise in the trading process, and vice versa. These three issues hold significance for several stakeholders. Firstly, policy makers who aim to improve trading activity as well as efficiency of the trading process may benefit from a clearer understanding of the links between return predictability and liquidity. Secondly, market makers on EU-ETS platforms, whose job it is to provide liquidity, platform operators and regulators may learn how the evolution of liquidity could affect the price discovery process. Thirdly, investors in carbon financial instruments may also find this study beneficial, as intraday prices rather than end of day prices mostly influence trader sentiment, and trades clustered around the opening/closing of the market (at which point it is most volatile - see Rotfuß, 2009) may be the basis for settling derivative contracts.

As market participants require time to incorporate new information into their trading strategies, a market deemed efficient over a daily horizon does not necessarily translate into a market that is efficient at every point during the day (see for example Fama, 1970, Epps, 1979, Hillmer and Yu, 1979, Patell and Wolfson, 1984, Chordia et al., 2008). Confirmation of this notion is available in the contributions of Cushing and Madhavan (2000) and Chordia, Roll, 
and Subrahmanyam (2005), showing that short-run returns can be predicted from order flows. However, Chordia et al. (2008) find that this predictability diminishes with improving market liquidity and across different tick size regimes on the NYSE. Similarly, Chung and Hrazdil (2010a) confirm the diminishing predictability proposition in a large sample analysis of NASDAQ stocks. These studies thus provide evidence of a strong relationship between liquidity and the enhancement of market efficiency through the impact of liquidity on the pricing process.

Another stream of literature examines the connection between liquidity and returns through the demand for premia when trading in illiquid instruments. Pástor and Stambaugh (2003) find a positive cross-sectional relationship between stock returns and liquidity risks. Their results are underscored by similar findings from Datar, Naik, and Radcliffe (1998) and Acharya and Pederson (2005). Similarly, Amihud (2002) documents evidence supporting the hypothesis that expected market liquidity provides an indication of stock excess return in a time series. This implies that the excess return, to some extent, typifies an illiquidity premium. Chang, Faff, and Hwang (2010) also report consistent findings for the Tokyo Stock Exchange.

Chordia et al. (2008) make an insightful argument for the relatedness of pricing efficiency and liquidity. Consider market makers in a hypothetical market struggling to sustain liquidity supply. This may be as a result of financial difficulties or over-exposure to untenable positions. Market makers may be relatively sensitive to significant buy orders for example, or an imbalance between buy and sell orders may imply that trading is taking place on the basis of private information. When such a scenario exists, pricing strain caused by arriving order flows potentially forces a brief deviation of prices from their underlying worth (hence inefficiency; see Fama, 1970). Order flow can thus give an indication of instrument returns, at least over short intervals (see also Stoll, 1978, Chordia and Subrahmanyam, 2004). Experienced and vigilant market participants (perhaps trading with algorithms for a significant 
proportion of the time) are likely to notice at least some of these deviations from random walk benchmarks, and thus become informed. Participants who remain unaware of the deviations can therefore be regarded as uninformed within the scope of those price deviations. The informed traders may tender market orders with the aim of profiting from the arbitrage opportunity. This is an informed trading activity. The choice of market orders is informed by the need to quickly profit before the arbitrage opportunity disappears, which would most likely be fleeting. The submitted orders from the arbitrageurs, assuming they are made in sufficient volumes and on time, are the ones that would lead to reduced pressure on the market makers' inventories. This then leads to the correction of the asset prices. According to Chordia et al. (2005), the correction in asset prices decreases return predictability. Since arbitrage traders (also known as informed traders - see Grossman and Stiglitz, 1980) are more likely to tender orders when the spreads are narrow, one would expect reduced return predictability when the market is more liquid than otherwise (see for example Peterson and Sirri, 2002, Brennan and Subrahmanyam, 1998 for the influence of liquidity on trading strategies). We investigate this hypothesis in a unique market, the EU-ETS, created as a result of climate change policy. ${ }^{2}$ In a market like the EU-ETS, which is set up to enable firms whose emissions are constrained under EU law (compliance traders) to exchange emission permits, the activities of arbitrageurs demand examination. Suppose arbitrageurs enter the market in order to exploit price deviations from instruments' underlying values. This may not enhance value for compliance traders, since such action may lead to failure of the scheme through the erosion of confidence. Even market makers, available in several EU-ETS platforms, may not consistently provide a sufficient level of liquidity throughout the trading day. However if, as proposed by the foregoing hypothesis, arbitrageurs' activity enhance pricing efficiency, then ultimately compliance traders may

\footnotetext{
${ }^{2}$ Our approach is clearly different from the spot-futures relationship approach usually adopted for measuring futures market efficiency (see for example Kellard, Newbold, Rayner, and Ennew, 1999).
} 
benefit from trading in a market with a diversified pool of traders, including non-compliance informed traders. Nonetheless, it appears that the activities of informed traders are limited in the EU-ETS. Bredin, Hyde, and Muckley's (2011) findings imply that liquidity traders dominate informed traders on the European Climate Exchange (ECX), the largest trading venue by volume in the EU-ETS. Thus informed trading activity might actually be limited enough to avoid impairing market integrity, but sufficient to enhance short run pricing efficiency as argued by Chordia et al. (2008). Several other papers also investigate informed trading in the EU-ETS (see as examples, Kalaitzoglou and Maher Ibrahim, 2013, Ibikunle, Gregoriou, and Pandit, 2013). Their findings suggest that informed trading activity in the EU-ETS is linked with improved market efficiency, as is the case in established markets.

This study mainly employs the short horizon order imbalance and return predictability regressions methodology of Chordia et al. (2008) to examine the relationship between liquidity and market efficiency. Our main findings are as follows: (i) Intraday return predictability is significantly reduced when the traded instruments are relatively more liquid, hence short horizon pricing is closely linked with liquidity - daily liquidity robustness tests and causality analyses also support this conclusion; (ii) Short run instrument trading return predictability is reduced as the market evolves/matures over a 40-month period, this indicates that pricing efficiency is enhanced progressively over the same period; (iii) The ECX instruments tested show improvement in terms of conformity with random walk benchmarks with each successive compliance period, thus implying a progressive reduction in noise trading. Overall, the findings suggest that the ECX has achieved a comparable level of informational efficiency to long established financial markets. By econometrically establishing an intraday link between return predictability and liquidity in the EU-ETS, this paper differs from the previous literature on trading activity in the EU-ETS. For example, Frino, Kruk, and Lepone (2010) and Benz and Hengelbrock (2009) investigate market liquidity, while Daskalakis (2013) and Montagnoli and 
de Vries (2010) investigate market efficiency in the EU-ETS. However, none of these papers examine possible links between carbon pricing and liquidity. Showing this link is important from both policy and economic perspectives. Although Ibikunle et al. (2013) suggest that carbon instruments with higher levels of liquidity (and lower information asymmetry) are priced more efficiently, they did not relate carbon pricing to liquidity. Furthermore, their paper mainly focuses on the comparison of carbon market trading activity during regular trading hours and after hours using a 10-month period data. Therefore, this current paper, based on a 40-month trading data, could be viewed as an extension of their work. ${ }^{3}$

The remainder of the paper is arranged as follows: in the next section we provide the background to the study by discussing the EU-ETS and the ECX. Section 3 discusses sample selection and describes the data. Section 4 reports our econometric methodology and the empirical findings, and finally Section 5 concludes.

\section{Background to this study}

\subsection{The EU Emissions Trading Scheme}

The Kyoto Protocol is an international accord on climate change, agreed in 1997, that came into force on $16^{\text {th }}$ February 2005. Under the treaty, developed countries and transition economies committed to achieving emission control targets in relation to their 1990 levels. For example, Japan committed to a $6 \%$ reduction and New Zealand to a $0 \%$ increase in emissions. The European Union was more ambitious and vowed to reduce its emissions to $8 \%$ below the 1990 levels, where the emission reduction burden per country varies considerably. Luxembourg's $-28 \%$ and Portugal's $+27 \%$ are the most and least ambitious reduction targets, respectively. Each party within the Kyoto Protocol can independently decide on the

\footnotetext{
${ }^{3}$ Kalaitzoglou et al. (2013) also examine informed trading in the EU-ETS by focusing on identifying the different agents at play in the carbon market.
} 
mechanisms used to achieve its emission control targets. The EU opted mainly to employ the emissions trading mechanism, as the EU-ETS (see Ellerman, Convery, and De Perthuis, 2010, Labatt and White, 2007).

The greenhouse gas permit trading market has since grown into a multi-billion dollar market with Europe leading in its development. The European emissions permit market has accounted for more than $95 \%$ of the global carbon market for any given year since $2006^{4}$ (see Kossoy and Ambrosi, 2010, Linacre, Kossoy, and Ambrosi, 2011). This is, however, set to change as New Zealand, China, Kazakhstan and Switzerland, as well as municipal and state governments in Japan, Canada and the United States, have all in recent years begun operating similar schemes. Australia adopted its market-based mechanism in 2011, with the aim to link up with EU-ETS in 2015. The situation at this time is, however, unclear following a recent change in government.

The EU-ETS is divided into three phases. Phase I (2005-2007) was a trial period before the commencement of the actual Kyoto commitment period (Phase II; 2008-2012). Phase II forms the basis of our investigations. The EU has committed to a post-Kyoto phase (Phase III, 2013-2020). This commitment has been supported by a global climate agreement, reached in Durban in December 2011. The Durban meeting also raises expectations with respect to the achievement of future global climate change agreements (see Ranson and Stavins, 2012). The EU-ETS operates as a cap and trade system, while allowing the use of certain external emissions permit instruments through the EU Linking Directive 2004/101/EC (see Flåm, 2007). This is the main driver for the EU's emissions reduction target of 8\% below 1990 levels over the Kyoto commitment period. The EU employs a 'burden sharing agreement' allowing it to

\footnotetext{
${ }^{4}$ The concept of permit trading is not, however, novel to the Kyoto Protocol or the EU-ETS - the most prominent example of emissions trading until recently has been the United States Acid Rain programme. The Environmental Protection Agency (EPA) has employed emissions trading as a policy tool to achieve emissions reductions since 1992.
} 
re-allocate emissions reduction targets within its member states, so as to allow emissions growth in less developed EU countries (Council Decision 2002/358/CE). Within its Kyoto target, the EU thus allocates individual targets to its constituent nations. This means more demanding targets for the larger European economies, such as Germany, than for the smaller ones. It then falls on the member countries to identify the installations affected within their borders under the aggregated reduction target. Iceland, Liechtenstein, and Norway (non-EU European countries) also participate in the EU-ETS (see Williams and Kittel, 2004). Overall, about 12,000 installations are subject to EU-ETS regulations, ${ }^{5}$ accounting for $40 \%$ of the EU's total greenhouse gas emissions. The European Union Allowance (EUA) is the trading permit unit (currency) in the EU-ETS. Project based instruments are, however, permitted for submission to a specified degree, depending on the phase. ${ }^{6}$ Annually, firms must submit EUAs equal to their verified net emissions for the preceding compliance year to EU authorities (see Daskalakis et al., 2011 for a detailed financial overview of the EU-ETS).

\subsection{Trading on the European Climate Exchange (ECX)}

The ECX is the largest carbon platform in the EU-ETS and by extension the world. In 2010, EUA carbon permits constituted more than $84 \%$ of the global carbon market value with approximately $73 \%$ traded as futures contracts (see Kossoy et al., 2010, Linacre et al., 2011). The ECX platform is the market leader in EU-ETS exchange-based carbon trading with more than $92 \%$ market share. Market volumes have also increased significantly from year to year since trading started in 2005. It is a derivatives platform and most of the trading activities have

\footnotetext{
${ }^{5}$ The sectors affected are electricity generators, mineral oil refineries, coke ovens, ferrous metals, glass, ceramic products and cement manufacturers to glass and pulp producers. Electricity generators are however the leading $\mathrm{CO}_{2}$ emitters. By Council decision, in 2012 the aviation sector was brought into the EU-ETS (Directive 2008/101/EC). A few other sectors are to be included from 2013 onwards.

${ }^{6}$ Project based permits include Certified Emission Reductions (CERs) and Emission Reduction Units (ERUs) from Clean Development Mechanism and Joint Implementation (JI) respectively (see Daskalakis, Ibikunle, and Diaz-Rainey, 2011).
} 
consistently occurred in its December maturity contracts. Ibikunle et al. (2013) estimate that since 2009 , at least $76 \%$ of the trading has occurred in the December contracts. The regular futures contracts are marketed on a quarterly expiry cycle: March, June, September and December. The underlying for each ECX EUA contract is 1,000 EUAs. The trading system is electronic and continuous. Official trading starts at 7:00hrs and ends at 17:00hrs UK local time from Monday to Friday. There is, however, a pre-opening trading period of 15 minutes to allow for participants to place early orders when planning for the trading day. The market thus opens for an initial period between 6:45hrs and 7:00hrs UK local time, with virtually no executed orders. The maturity date for the contracts is the last Monday of the traded month, with physical settlement occurring within three days following expiry. Carbon Financial Instruments (CFI) trading on the ICE ECX platform is done electronically on the ICE platform. The ICE Futures Europe platform is accessible only to members for order placement. All valid orders and their corresponding executions are anonymous. The electronically executed trades pass through the so-called Trade Registration System (TRS) for account allocation.

\section{Data}

The sample period runs for most of Phase II of the EU-ETS. We compute all of the order imbalance, liquidity and futures returns measures on an instrument-specific basis. The use of instrument-specific variables for the examination of pricing dynamics is grounded in the microstructure literature (see for example Brennan, Jegadeesh, and Swaminathan, 1993, Lo and MacKinlay, 1990). Serial dependence between days is approximately zero for dynamic instruments, which are too heavily traded for anomalies to exist for very long (see Chordia et al., 2005). An examination of connections between liquidity and pricing on a platform such as the ECX (with actively traded instruments) should therefore be centred on intraday trading. Serial dependence in intraday returns has already been reported by Conrad, Rittler, and Rotfuß 
(2012). The phenomenon is a result of persistence in order flow, which suggests that orders move significantly in a particular direction. If the change in direction is for buys, then the returns become positively persistent, if it is for sells, the returns will turn persistently negative. This persistence in returns will subsist, usually over short intervals, until the order flow is balanced by countervailing orders (see Chordia et al., 2005 for a comprehensive analysis of this process). The carbon futures order imbalance analysis of Mizrach and Otsubo (2014) using daily measures will not, therefore, suffice. As Mizrach et al. (2014) focus on daily order imbalance, the results have no relevance for our research questions. We use 15-minute intervals as the focus of this study rather than the five-minute intervals used by other studies (see as examples Chordia et al., 2008, Chung et al., 2010a, Chung and Hrazdil, 2010b) based on two considerations:

1. Concerns regarding non-trading for less actively traded instruments on ECX: since on EU-ETS derivative trading platforms the nearest maturity contracts usually account for about $80 \%$ of trades in emission permits, non-trading is taken into account by extending the interval to 15 minutes.

2. Theoretically, a predictive connection between order imbalances and returns in a dynamic market should not endure for more than a matter of minutes (for less than 60 minutes according to Chordia et al., 2005), since market inefficiencies create arbitrage opportunities. Trading activity on account of this in turn help regain a measure of pricing efficiency. Hence, while non-trading remains an issue, the time interval chosen must be short enough to capture the inefficiencies in trading activity. This informs the decision not to extend the interval beyond 15 minutes. 
Based on the foregoing and the problem of determining serial dependence in the presence of non-trading, we restrict our analysis to instruments that are traded relatively frequently for a specific compliance year. ${ }^{7}$ We also follow Chordia, Roll, and Subrahmanyam (2001) in excluding instruments with differing trading characteristics to the major CFIs traded on the exchange. Thus we exclude EUA Daily futures and EUA spreads. Ultimately, only five EUA futures contracts with varying trading years are retained in the sample. These are the December expiry contracts for 2008, 2009, 2010, 2011 and $2012 .{ }^{8}$ Crucially, these December maturity contracts account for more than $76 \%$ of daily trading volume on the ECX for the period under investigation. The dataset obtained directly from the ICE/ECX London platform comprises of all intra-day tick-by-tick ECX EUA futures contracts on-screen trades on the ECX platform from January 2008 through to April 2011. The dataset contains date, timestamp, market identifier, product description, traded month, order identifier, trade sign (bid/offer), traded price, quantity traded, parent identifier and trade type. The dataset is split into four compliance periods of Phase II, the 2008, 2009, 2010 and 2011 compliance years. Tick size for the entire period is $€ 0.01$, having been reduced from $€ 0.05$ on $27^{\text {th }}$ March 2007 (during Phase I). The division based on regulatory compliance periods is exogenous and provides for a practical basis to examine the effect of liquidity on return predictability.

\subsection{Order imbalance and return measures}

\footnotetext{
${ }^{7}$ If we apply 5-minute intervals as the basis for the measures, we would be forced to examine only one contract per year for the period under consideration due to non-trading effects in the other contracts, hence we use 15minute intervals. In any case, we conduct a robustness analysis using only the highest volume contract, which is the nearest maturity contract, per year. We find that sampling at 5-minute intervals leaves our inferences unchanged.

${ }^{8}$ The delineation of the contracts analysed for each year, based on trading activity constraints, is as follows: For Year 2008, the December 2008, 2009 and 2010 maturities are used; for Year 2009, December 2009, 2010 and 2011 maturities are used; for Year 2010, December 2010, 2011 and 2012 maturities are used and the December 2011 and 2012 maturities are used for Year 2011.
} 
We begin our enquiry into the links between liquidity and pricing by computing the variables employed for most of this paper. In the dataset, all trades are labelled as either buyer initiated or seller initiated, hence we do not need to algorithmically allocate trade classifications. We use two order imbalance methods based on nominal trades and the euro weight of trades respectively. Nominal order imbalance $\left(O I B Q_{t}\right)$ for each CFI and for each 15-minute interval is calculated using equation (1), while the euro order imbalance $\left(O I B \epsilon_{t}\right)$ is simply the weighing of (1) with euro trading value of the trades, as shown in equation (2). ${ }^{9}$ The nominal order imbalance is non-weighted and thus fails to account for the economic significance of the trades, unlike the euro order imbalance measure. For most of the analysis we therefore employ the latter measure of order imbalance.

$$
\begin{aligned}
& O I B Q_{t}=\frac{\left(B U Y_{t}-S E L L_{t}\right)}{\left(B U Y_{t}+S E L L_{t}\right)} \\
& O I B €_{t}=\frac{\left(€ B U Y_{t}-€ S E L L_{t}\right)}{\left(€ B U Y_{t}+€ S E L L_{t}\right)}
\end{aligned}
$$

For each CFI, the measures are calculated for every 15-minute interval in a trading day. In computing the 15-minute returns variable, we use the last transaction prices for every 15minute period. ${ }^{10}$ Although returns are viewed as being less biased when computed from quotes than from transaction prices, we face two challenges in computing from quotes. First, heterogeneities exist for trading rates of occurrence for CFIs on the ECX as a result of the high level of differing trading frequencies. Potentially, the results will be biased and contradictory since the method could result in returns being computed over different spans for different CFIs. One should also be mindful that computing returns with transaction prices could be affected by bid-ask bounce. However, the summary statistics of trading prices for each of the four

\footnotetext{
${ }^{9}$ We also examine the possibility that our order imbalance measures may reflect exogenous shocks by computing absolute values for liquid and low liquidity periods as described in page 259 of Chordia et al. (2008) for robustness. As reported in Section 4.3, the results show that there is very low variation across the liquid and illiquid days; hence the results are not affected by exogenous impact.

${ }^{10}$ We also use the mid-point of the last bid and ask transaction prices for every 15 -minute period with similar outcomes.
} 
compliance periods suggests that this is not a significant source of concern in the ECX dataset. Also, since our analyses are based on contract-specific measures, we mitigate the problem of non-synchronicity. In addition, when a contract fails to trade at $t-1$, we do not use it when constructing the market aggregate measure at time $t$. We therefore employ the transaction prices for computing the return variable for each fifteen-minute period such that the return for 10.15am is computed using the last trade at 10:00am and the last trade at 10:15am. For all analyses utilising lagged estimates, the earliest 15-minute interval for each trading session/day is removed since it is connected to the lagged interval of the foregoing trading session.

\subsection{Liquidity measures}

We adopt two measures of short-term liquidity constructed using transaction prices at regular 15-minute intervals. Relative spread, the main measure of liquidity used, is given as the best/highest traded bid price minus the best/lowest traded ask price. This is then divided by the average of the best traded bid and best traded ask price for every 15-minute period. Traded spread, the second measure of liquidity employed, is defined as the best traded bid price minus the best traded ask price over the same interval. ${ }^{11}$ The traded spread is computed for use in robustness analysis and most of the results for it are not presented in this paper.

Contract-specific daily bid-ask spread measures are first computed and then aggregated cross-sectionally across the CFI samples to obtain a market-wide liquidity value. Four exogenous liquidity periods are identified based on compliance periods available in Phase II of the EU-ETS. The sample thus spans 40 -months of trading based on available data. Period (i) runs from $2^{\text {nd }}$ January 2008 until December $31^{\text {st }} 2008$; period (ii) from $2^{\text {nd }}$ January 2009 until December $31^{\text {st }} 2009$; period (iii) from $4^{\text {th }}$ January 2010 until December $31^{\text {st }} 2010$; and period

\footnotetext{
${ }^{11} \mathrm{We}$ also compute the measures with traded bid and ask prices at the stroke of each 15-minute period. The results are very similar with no material variation in values.
} 
(iv) from $3^{\text {rd }}$ January 2011 until April $29^{\text {th }} 2011$. Period (iv) is restricted by data availability for this study. The four periods correspond to Phase II-Year I, Phase II-Year II, Phase II-Year III and Phase II-Year IV respectively. Since they jointly represent two-thirds of Phase II, they have a good degree of representativeness.

\section{Results and discussion}

\subsection{Summary statistics}

Table 1 shows summary statistics for traded spread, relative spread, market returns and the two order imbalance measures. The samples are representative of values for all contracts examined in the assigned periods, with the exclusion of those missing observations (i.e. when no trading occurs). The statistics clearly show a strong improvement in liquidity over the four compliance periods. The mean traded and relative spread measures for Phase II-Year I are $€ 0.1197$ and 0.0043 respectively. These decrease substantially by $74 \%$ and $56 \%$ to $€ 0.031374$ and 0.001918 in Year IV for the traded and relative spreads respectively. Order imbalance measures generally increase in magnitude, progressing from negative $(-0.005787$ and $€-$ $0.08279)$ in Year I to positive values in the Year IV (0.02042 and $€ 0.002767)$ for $O I B Q_{t}$ and $O I B \epsilon_{t}$ respectively. The statistics are similar to those of Chordia et al. (2008) and thus show a market with an increasing ratio of bid trades to ask trades. Markets with the highest levels of pricing efficiency usually record more bid than ask trades, since arbitrage traders operate from neutral positions, from which they bid for opportunities.

\section{[TABLE 1 ABOUT HERE]}

\subsection{Correlations}

Table 2 shows correlation coefficients for (lags of) the two order imbalance measures and the futures returns. As one would expect, and consistent with Chordia et al. (2008), the 
order imbalance measures are clearly highly correlated, except for in Year I, however all are statistically significant at the $1 \%$ level. The return is not as highly correlated with the order imbalance measures. These results are more in line with correlations between daily horizon measures, as reported in Chordia et al. (2005), where very low correlations are reported between daily order imbalance measures and returns. Although it may be surprising that we record statistically significant negative correlations for Year II, this is not unusual, especially when frequencies of less than five minutes are used in computing the return and order imbalance measures (see Chordia et al., 2005). For other periods and for the $O I B Q_{t}$ measure, the correlation coefficients are positive and also statistically significant. For $O I B \epsilon_{t}$, only Year III returns a coefficient that is not statistically significant at all levels tested. The initial expectation here is that of a high correlation of returns with the order imbalance measures. Although this is not the case, the correlation analysis results are by no means conclusive evidence of the link between returns and order imbalance on the ECX. It is important to understand that while there are already several investment vehicles on the carbon trading platform, the main aim of the market is not for wealth creation, but rather to establish an emission-constrained economy. This complicates the picture for the market efficiency-liquidity relationship we are investigating.

\section{[TABLE 2 ABOUT HERE]}

\subsection{Predictive regressions, market efficiency and liquidity}

We employ Chordia et al. (2008) returns predictability model (3) to estimate the level of short-horizon efficiency. If rett is the contract return and OrderImbalancet-1 corresponds to either of $O I B Q_{t}$ or $O I B \epsilon_{t}$ during the previous 15-minute interval, then;

$$
\text { ret }_{t}=\alpha+\beta_{1} \text { Order Imbalance } \text { t-1 }_{t}+\varepsilon_{t}
$$


Based on results of the correlation analysis, the expectations for the predictive regressions are not very clear. Table 3 reports results for the predictive regressions of 15 -minute returns on lag order imbalance measures. Panel A shows the results for regressions run with the $O I B Q_{t}$ measure and Panel $\mathrm{B}$ for the $O I B \epsilon_{t}$ measure. The results are not stable across the various periods for both regressions. For the regressions run with the entire sample, the results suggest that on the ECX, lagged order imbalance is not a significant predictor for short-run returns and this is consistent for both order imbalance measures. However, different findings are obtained for the period-based results. For example, in Panel A, for Phase II, Year I, Phase II, Year III and Phase II, Year IV, the $O I B Q_{t}$ coefficients (significance-values) are $0.000325(0.08), 0.000368(0.02)$ and $0.000441(0.03)$ respectively. The $\mathrm{R}^{2}$ for the two periods are $0.025 \%, 0.022 \%$ and $0.0054 \%$ respectively. Similarly, and more significantly, in four of the periods considered using the $O I B \epsilon_{t}$ measure, Panel B reports statistically significant coefficients for three of the periods. In Years I, II and IV of Phase II trading, the $O I B \epsilon_{t}$ coefficients (significance levels) are 0.000582 (5\%), $0.000547(10 \%)$ and $0.000436(10 \%)$ respectively. The $\mathrm{R}^{2}$ values for the three periods are respectively $0.023 \%, 0.02 \%$ and $0.009 \%$. Thus, if the overall estimates for the 40 -month period examined are not considered, we can see the influence of order imbalances in the determination of market returns. It is evident that this explanatory power decreases with each passing period, which is consistent with Chordia et al. (2008). These results indicate that return predictability decreases over the period under examination, and thus as argued by Chordia et al. (2008), the reduction in return predictability enhances pricing efficiency.

\section{[TABLE 3 ABOUT HERE]}

Considering the trading frequency on the ECX and the intervals of 15-minutes examined, these values are substantial and provide a basis to explore further the hypothesis that lagged order imbalance influences short-run returns. Since there is a suggestion of period 
dependency to the estimates, we examine next how pricing has evolved over the four periods. We run monthly predictive regressions for the 40 months under observation, starting with January 2008 and ending with April 2011. For this purpose and subsequently, we use the $O I B \epsilon_{t}$ as the sole order imbalance measure, since it represents the economic significance of the trading imbalance and its results in Table 3 are more significant. We expect that as the market's pricing efficiency improves, the power of order imbalance in predicting short-run returns diminishes; hence $\mathrm{R}^{2}$ values are expected to drop progressively over the entire period. Figure 1 shows a plot of the monthly regressions $\mathrm{R}^{2}$ values and $\mathrm{t}$-statistics for the entire period. The plot shows the $\mathrm{R}^{2}$, decreasing from a height of $1.4831 \%$ in September 2008 to $0.0004 \%$ in February 2011. The t-statistic values have remained largely stable and positive, especially over the April 2009April 2011 period. The values hit a peak of 3.81 in February 2008 and end with a value of 1.08 in April 2011.

\section{[FIGURE 1 ABOUT HERE]}

In keeping with Chordia et al. (2008) and Chung and Hrazdil (2010a), we next examine the connections between liquidity and market efficiency, which is the main object of this study. The most straightforward means to proxy liquidity is to examine the bid-ask spread. Traded spread is therefore measured as the highest bid minus the lowest ask price. A variant of this (see Amihud and Mendelson, 1986) is the relative spread. It is defined as the traded spread divided by the average of the bid and ask prices. Although liquidity is clearly an important component of the cost of trading, Amihud (2002) suggests an alternative that is argued to more directly proxy liquidity. In less liquid markets, any given level of trading volume will give rise to a greater price response than in liquid markets. The Amihud (2002) ratio is therefore defined as the ratio of the absolute return to trading volume. However trading volume is likely to be greater for economically larger instruments, thus creating a large firm bias. For robustness, we 
therefore also adopt the Florackis, Gregoriou, and Kostakis (2011) measure, in which volume in the Amihud (2002) ratio is replaced by the turnover ratio. The principle is similar, in that a greater price movement is anticipated for illiquid markets for any given proportion of the asset traded. The advantage of this measure over the Amihud (2002) ratio is that there is no significant correlation between instrument trading size and the turnover ratio. The Amihud (2002) and Florackis et al. (2011) ratios are given as equations (4) and (5) below respectively:

$$
\begin{gathered}
\text { Amihud }_{i t}=\frac{1}{D_{i t}} \sum_{d=1}^{D_{i t} \frac{\left|R_{i t d}\right|}{V_{i t d}}} \\
\text { Florackis }_{i t}=\frac{1}{D_{i t}} \sum_{d=1}^{D_{i t}} \frac{\left|R_{i d d}\right|}{T R_{i t d}}
\end{gathered}
$$

where $R_{i t d}, V_{i t d}$ and $T R_{i t d}$ are the return, euro volume and turnover ratio of EUA futures contract $i$ on day $d$ at month $t$ and $D_{i t}$ is the number of trading days in month $t$ for EUA futures $i$. Larger values therefore indicate that the market is less liquid.

Figure 2 presents the time series plot of relative and traded spread over the 40 -month period under observation. ${ }^{12}$ As can be seen, both measures of liquidity are consistent. Conspicuously, there is a sustained narrowing of the market spread over the entire period, suggesting that liquidity improves with time on the ECX. ${ }^{13}$ Furthermore, there seems to be a noticeable blip around the start of trading for each period. This shows a temporary loss of liquidity, perhaps present as a result of some form of calendar effect. ${ }^{14}$

\footnotetext{
${ }^{12}$ Further, we employ the traded spread in all other sections of this paper for robustness examinations. In all instances, the results yielded are not materially different from those yielded by our use of the relative spread. The results presented in this paper are thus robust to substitute liquidity proxies.

${ }^{13}$ Given the period examined in this paper, it is possible that the tapering off of the effects of the global financial crisis might have influenced liquidity and the enhancement of pricing efficiency during the Phase II of the EUETS. However, this consideration has no implication for the main focus of this study - the intraday links between return predictability and liquidity. This is because there is no basis to expect that illiquidity is jointly determined with signed order imbalances (see also Chordia et al., 2008).

${ }^{14}$ Ibikunle and Gregoriou (2011), using the market model (Brown and Warner, 1985), examine calendar effects on the European Energy Exchange (EEX) carbon platform and find no significant effect. We nevertheless apply several dummy regressions to capture the effects of specific dates in further analyses. As discussed in Section 4.3, the dummy coefficients and respective t-statistics imply that the events have no intraday impact on our results.
} 


\section{[FIGURE 2 ABOUT HERE]}

The results for the price impact ratios are presented in Figure 3. It can be seen that the evolutions of the measures are consistent with Figure 2.

\section{[FIGURE 3 ABOUT HERE]}

In reference to Blume, Mackinlay, and Terker (1989) and Cox and Peterson (1994), the impact of illiquidity is more significant during periods of very low liquidity. In view of this, and in order to maintain consistency with Chordia et al. (2008), we split the days in our sample based on those that are considered liquid and those that are relatively illiquid. The illiquid days are defined as those whose average relative spread for that day is at least one standard deviation above the mean relative spread for a surrounding period over $(-30,+30) .{ }^{15}$

In Table 4, we present descriptive statistics for relative spreads on high and low liquidity days over the 40-month period. The general trend is that the number of illiquid days, as a proportion of the total number of trading days in the respective periods, decreases from year to year. In Phase II, Year I, Phase II, Year II, Phase II, Year III and Phase II, Year IV ${ }^{16}$, for example, the proportion of illiquid days as percentages of total number of trading days are $13.58 \%, 12.89 \%, 10.87 \%$ and $9.33 \%$ respectively. The gradual improvement evident here is consistent with Figures 2 and 3. If considered in tandem with Figure 1, there is a suggestion

\footnotetext{
${ }^{15}$ We also employ the $(-60,+60)$ window as used by Chung and Hrazdil (2010a), with no substantial differences in the number of liquid and illiquid days. For robustness, we econometrically estimate effective half-spread for days in a randomly selected month in each year using the Huang and Stoll (1997) spread decomposition model. The distribution of liquid/illiquid days observed is not qualitatively dissimilar to the one we use above.

${ }^{16}$ In Year IV, the 7 illiquid days have lower spread values than the liquid days. This underscores the limitations to our definition of illiquid days, which we control by using another window and seeing very small qualitative differences in the distribution of illiquid days. Suppose we have a period of low spreads leading to April (when compliance traders must submit emission permits) as a result of perceived increase in trading activity, and suppose most of our illiquid days are around this period. Then we are likely to obtain 'illiquid' days with lower average spread than the average of the vastly larger number of liquid days. This is plausible since our definition of illiquidity is relative to only a given number of surrounding days in the year for every illiquid day. Moreover, the differences in the values are so small that they are not statistically different from one another, even at the $10 \%$ level. The same case is made for the mean values in Year III.
} 
that market efficiency improves when the market is more liquid. ${ }^{17}$ We next test for this empirically.

\section{[TABLE 4 ABOUT HERE]}

In order to empirically analyse the effect of liquidity on the evolution of market efficiency, we interact the order imbalance variable $\left(O I B \epsilon_{t}\right)$ with a low-liquidity day dummy. For every day on which the average relative spread is at least one standard deviation above the mean relative spread for a surrounding period over $(-30,+30)$, the dummy takes on the value of 1 and 0 otherwise. If $I L D_{t}$ corresponds to the low liquidity dummy on day t, then model (3) becomes;

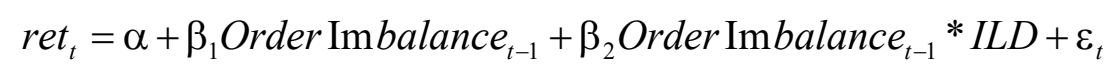

The regression model (6) is thus run such that on low liquidity days, the lagged $O I B \epsilon_{t}$ variable with the dummy interaction becomes $O I B \epsilon_{t-1}$ and 0 on other days ${ }^{18}$. In Table 5, we present the results for the regression analysis. In this analysis, we focus on the significance of the interaction term, coefficient $\beta_{2}$. The coefficients for three of the examined periods are positive and statistically significant. For Phase II, Year I, the coefficient is 0.003341 ( $p$-value $=0.00$ ). Also for Phase II, Year II, the coefficient is 0.003313 (p-value $=0.00$ ). The trend holds also for the final year under consideration, Phase II-Year IV, with a coefficient of 0.0021 (p-value $=0.03)$. As in Panel B of Table 3, the Phase II, Year III period does not conform to the general trend observed for the other periods. The highest coefficient value is recorded for Year I, and decreases from then on until a slight rise in Year IV. One reason that could be advanced for the

\footnotetext{
${ }^{17}$ The percentage proportion of median relative spread on illiquid days to liquid days for Years I, II, III and IV are $119 \%, 125 \%, 101 \%$ and $90 \%$ respectively. These values (except for Year IV for which we have data for only $1 / 3$ of the year) is consistent with the expectation that the average spread for low liquidity days will be higher than that of liquid days.

${ }^{18}$ We also carry out robustness tests by including dummies for specific day-after events such as the submission of annual emission reports, national allocation plans (NAP) and annual emission results announcements. We include dummies for days preceding specific holidays in the U.K. The resultant coefficients show that the events are not significant to our investigations on intraday basis; also our earlier results are not materially altered.
} 
deviation of Phase II, Year III (i.e. 2010) is the inability of the United Nation's Conference of Parties to reach a highly expected and ambitious agreement on global climate policy in December 2009 at Copenhagen. The failure to achieve the expected goals set for the Copenhagen conference thus appear to have impacted the carbon markets in subsequent months.

\section{[TABLE 5 ABOUT HERE]}

The coefficients on lagged order imbalance $\left(\beta_{1}\right)$ are all statistically insignificant. This implies that where lagged order imbalance is found to affect/predict returns, it does so only when the market is illiquid. Results in Table 5 show that this finding on illiquidity and lagged order flow explains a greater proportion of variation in returns. Consistent with NASDAQ and NYSE evidence by Chung et al. (2010b) and Chordia et al. (2008) respectively, the $\mathrm{R}^{2}$ values decrease from Year I to Year IV. For example, in Year I, the $\mathrm{R}^{2}$ is 0.0038 , but by Year IV, this has diminished to 0.000451 . This observed decline in the explanatory power of the periodic models and their significance is consistent with the gradual improvement in liquidity reported in Figures 2 and 3, as well as in Table 1. Adjustments in liquidity thus affect levels of market efficiency. The liquidity improvements over 15-minute periods, which lead to enhanced pricing efficiency, may be connected with the activities of arbitrageurs as reported by Kalaitzoglou et al. (2013). The reported dominant role of liquidity traders in the EU-ETS, as reported by Bredin et al. (2011), is important for the provision of counterparties for arbitrageurs when order imbalance occurs or intensifies.

Exogenous impacts can lead to extreme order imbalances, which can in turn result in a loss of liquidity. Thus in our analysis, using the low liquidity dummy on $O I B \epsilon_{t}$ to determine the impact of liquidity, rather than capturing the effect of liquidity in improving market efficiency we may well have been picking up the impact of exogenous shocks. In order to examine this possibility we therefore construct absolute order imbalances for liquid and illiquid 
periods following the method of Chordia et al. (2008). We construct these measures for all four of the periods and find only minimal variations across both the liquid and illiquid days. This result implies that our results indeed capture the real role of liquidity in improving market efficiency, along with several other checks mentioned in the footnotes. As discussed by Chordia et al. (2008), it is illogical to assume that illiquidity is jointly determined with signed order imbalances. If an illiquidity-inducing event that is exogenous to the market does occur, one should expect to see as fewer buy orders as sell orders.

\subsection{Granger causality analyses}

As an additional check of robustness and to further explore the notion that narrowing spreads on day $t$ results in improved pricing on day $t+1$, we carry out Granger causality tests (see Granger, 1969) relating past values of the liquidity proxy to order imbalance. ${ }^{19}$ This is undertaken by estimating a vector autoregressive model (VAR), in this case with two dependent variables. The first, $\varphi$, is the daily relative spread liquidity proxy. The second, $\delta$, denotes the daily mean of the 15-minute Euro order imbalance measure for each EUA futures contract traded. The lag length, $l$, is chosen to purge autocorrelation. This results in a model of the following form:

$$
\begin{aligned}
& \varphi_{t}=\alpha_{0}+\alpha_{1} \varphi_{t-1}+\ldots+\alpha_{l} \varphi_{l-1}+\beta_{1} \delta_{t-1}+\ldots+\beta_{l} \delta_{l-1}+\varepsilon_{t} \\
& \delta_{t}=\alpha_{0}+\alpha_{1} \delta_{t-1}+\ldots+\alpha_{l} \delta_{l-1}+\beta_{1} \varphi_{t-1}+\ldots+\beta_{l} \varphi_{l-1}+\mu_{t}
\end{aligned}
$$

\footnotetext{
${ }^{19}$ The structure of the VAR analysis in this section is different from that of the preceding analysis, where we aim to capture return predictability, which could only be adequately investigated on an intraday basis. Conducting the VAR analysis using daily frequency data following the aggregation of 15-minute interval data into daily measures should have no implication for the results other than to reduce the probability of establishing a statistical relationship. This is because a reduction in the degrees of freedom afforded by the use of daily aggregates of our liquidity and order imbalance measures should make it harder to establish a statistical relationship. Therefore, the results we obtain only serve to underscore the fact that past values of liquidity proxies do indeed help to explain variations in pricing.
} 
The equations in model 7 are estimated simultaneously for each of the four periods. The statistics presented in Table 6 are the Wald statistics for the joint hypothesis:

$$
\beta_{1}=\beta_{2}=\ldots=\beta_{l}=0
$$

for each of the equations in (7). The null tested is that $\delta$ does not Granger-cause $\varphi$ in the top equation and that $\varphi$ does not Granger-cause $\delta$ in the bottom equation. We run these equations on a contract-specific basis for each period; the results are presented in Panel A of Table 6.

\section{[TABLE 6 ABOUT HERE]}

Panel A shows that the hypothesis that liquidity improvements on a given day do not inform pricing during the next is strongly rejected for all tested contracts for the first three periods. For the fourth period, which includes trading data for only 82 days of trading, we cannot reject this hypothesis. There is also evidence of two-way causation with respect to the Dec-2009 (Phase II, Year II), Dec-2010 (Phase II, Year III), Dec-2011 (Phase II, Year III) and the Dec-2012 (Phase II, Year III) EUA futures contracts. Broadly therefore, the evidence of a two-way causation cannot be conclusively established since it affects contracts only in specific periods. Further, the same contracts are not affected uniformly across all periods in which they are tested. In order to explore further the possibility of bi-directional causality in the futures contracts, we also run the VAR on a contract-specific basis without recourse to sub periods. The results are presented in Panel B of Table 6. Again, there is substantial evidence of Granger causality running from liquidity to order imbalance. However a two-way causation is only observed in the case of the Dec-2012 contract. The evidence in Table 6 therefore further confirms our overriding hypothesis that liquidity on emissions permit trading platforms results in more efficient trading. 
4.5. Variance ratios: measuring randomness of returns

A key assertion in this paper is that the predictability of intraday (short-run) return from order imbalances (order flow) is an inverse indicator of pricing efficiency. Chordia et al. (2008) propose another procedure involving the measuring of randomness of returns series. This requires the comparison of variance ratios over short and long horizons. The variances of longhorizon returns are divided by the estimated variance for returns over shorter intervals. For a market in harmony with the random walk process, the variance of returns measured over longer horizons is equal to the sum of variances of shorter horizon returns as long as the summation of the shorter horizons is equal to that of the longer horizon. Based on our earlier results, we maintain the hypothesis that, during liquid spells, there will be fewer deviations from random walk benchmarks, i.e. the variance ratios will be closer to one for each instrument. We concede the point made by Grossman and Miller (1988) that divergence from a random walk can be induced by inventory related issues due to return serial correlation. However in a largely efficient market arbitrage opportunities created by this deviation will lure participants into providing the required liquidity, hence the divergence from a random walk will be very much temporary, even if market makers cannot absorb orders (see also Admati et al., 1988).

\section{[TABLE 7 ABOUT HERE]}

For each instrument within each period, we compute 15-minute returns as described in section 3 and also for opening to closing returns for all trading days. We then compute the variance ratio by multiplying the 15-minute return variance by the number of 15 -minute periods in a trading day. In a market conforming to a random walk process the variance ratio values will be close to one. Table 7 presents the results of the Variance ratio analysis for contracts traded in each period, as well as value weighted variance ratios for each period. The weight employed is the total trading value per instrument. As expected, consistent with Figure 2 and Table 1, the overall variance ratio values decrease progressively from 3.74 in Year I to 1.39 in 
Year III. These values rise slightly to 1.42 in first four months of Year IV. It is therefore evident that as the market becomes more liquid and the EUA futures contracts are traded faster with minimal impact on their prices, the market approaches a variance ratio of unity; that is, it conforms more to the random walk process. Given that the variance ratio analysis implicitly assumes that deviations from the random walk benchmark reflects higher levels of noise in the trading process, the results suggest that noise trading generally decreased from 2008 to 2011 in the EU-ETS. A decrease in trading-related noise also implies higher market quality, and thus we confirm earlier results that pricing/trading efficiency has improved within the sample period. Another trend in Table 7 is the propensity for the least traded contracts during a specific period to have the highest variance ratios. For example, in Year I, the Dec-2010 contract is the least traded and has a ratio of 16.61 , more than seven times the value for the most traded contract in Year I (Dec-2008). The ratio disparity is, however, less severe in later years. For example, the Dec-2012 ratio in Year III is only about twice the value of that of the Dec-2010 contract. The results therefore support the expectation that divergence from random walk benchmarks is less severe if markets are liquid.

\section{Concluding discussion}

The EU-ETS is the largest emissions trading experiment in the world. Although there are now about 17 other compulsory schemes elsewhere in the world, the success of the EUETS would still provide a strong impetus for the formulation of a truly global market-driven climate change policy given that it drives more than $90 \%$ of global carbon trading. However, to the best of our knowledge, no study has been undertaken on the contemporaneous linkages between pricing efficiency and liquidity in the EU-ETS. Our work focuses on the link between efficiency and liquidity and hence contributes to the understanding of this market and provides evidence of its efficacy. Theoretically, returns predictability on an efficient market should be 
momentary, infrequent and, in the event it occurs, arbitrageurs should provide the necessary pool for order absorption.

In this paper, we investigate the predictability of returns from intraday order flow across 40 months of trading on the world's largest emissions trading platform. We provide evidence that while return predictability occurs on the platform, it has significantly decreased since the start of Phase II in 2008 and continues to decline over the entire period investigated. The prices of each instrument are thus closer to the random walk benchmark as the scheme evolves.

Our results are consistent with previous studies which have investigated separately both liquidity and market efficiency. For example, Frino et al. (2010) find that aggregate long-term liquidity improves over the course of Phase I and during the early months of Phase II. Ibikunle et al. (2011) show liquidity improvements on account of enhanced regulations early on in Phase II, while Benz et al. (2009) also report an improvement in quarterly measures of liquidity over time in Phase I. With respect to market efficiency of the EU-ETS in Phase II, our results are in line with Daskalakis (2013), Ibikunle et al. (2013) and Montagnoli et al. (2010). Indeed the results of most of the existing studies investigating either the liquidity or efficiency of carbon financial instruments are similar to our findings. However, one recent study on European carbon market efficiency that appears inconsistent with the general view is that of Charles, Darné, and Fouilloux (2013). Their suggestion that the European carbon market in Phase II might has been inefficient is related to their approach to estimating and defining market efficiency, both of which involve estimating whether spot and futures instruments in the EUETS conform to the cost of carry relationship.

Although the aforementioned studies examine market liquidity or efficiency during various trading phases of the EU-ETS, none links market efficiency to market liquidity. Furthermore, these studies do not provide the level of intraday exposition we have presented in this paper, since we examine pricing and liquidity dynamics over 15-minute periods. This 
level of analysis is important to several stakeholders, especially carbon instruments' investors, who are most active across the trading day. This is because intraday prices usually have the most influence on trader sentiment, and thus intraday trading activity better captures market dynamics.

Based on our results and the assumption that the loss of market efficiency leads to arbitrage openings, one can conclude that arbitrage activities, especially when the market is more liquid, lead to more efficient pricing. Hence, we provide the first evidence that for emissions permit trading platforms, liquidity enhances pricing efficiency. The importance of our study is further underscored by the fact that the cost of hedging increases when efficiency decreases in futures markets (see Krehbiel and Adkins, 1993). Therefore, the findings in this paper have significant implications for more than just academic stakeholders. A number of policy makers and key stakeholders around the world remain sceptical of the effectiveness of market-led approaches in reducing GHG emissions. By testing the pricing efficiency of the ECX over a 40-month period, we provide a starting point to examine the validity of this scepticism. Policy makers (including departments responsible for the environment, energy policy, fiscal policy, trade policy and competitiveness) around the world could be reassured that improving market liquidity improves the financial instrument pricing capacity of carbon markets. This understanding could be crucial as representatives of more than 190 countries gather in Paris in December of 2015 to negotiate a new global climate change legislation. Our research also has implications for practitioners who must trade on or via EU-ETS platforms in order to comply with EU Climate Change legislations. For example, compliance traders can benefit from a stronger understanding of the carbon market dynamics. This understanding can be employed in formulating carbon investment strategies and effective carbon risk management. While this paper investigates the evolving relationship between market liquidity and efficiency over an extensive period in the EU-ETS, our approach, based on intraday order 
imbalance, return and liquidity dynamics, means that we are unable to directly/adequately test the efficiency impact of events in the EU-ETS. This is because there is no basis to expect that liquidity is jointly determined with order imbalances. Therefore, future research could consider a different analytical approach aimed at testing the efficiency impacts of key policy and economic events. Although several papers have conducted event studies to examine the impact of events on carbon prices, none has directly investigated the effect of these events on pricing efficiency. Furthermore, the ECX from which we have sourced our data is the most liquid platform in the EU-ETS and in the world. Future research could therefore investigate return predictability in relation to liquidity on less liquid platforms as well. 


\section{References}

Acharya, Viral V., and Lasse Heje Pedersen. (2005). Asset pricing with liquidity risk. Journal of Financial Economics, 77(2), 375-410.

Admati, AR, and P Pfleiderer. (1988). A theory of intraday patterns: volume and price variability. The Review of Financial Studies, 1(1), 3-40.

Amihud, Yakov. (2002). Illiquidity and stock returns: cross-section and time-series effects. Journal of Financial Markets, 5(1), 31-56.

Amihud, Yakov, and Haim Mendelson. (1986). Asset pricing and the bid-ask spread. Journal of Financial Economics, 17(2), 223-249.

Benz, Eva, and Jordis Hengelbrock. 2009. Price discovery and liquidity in the European $\mathrm{CO}_{2}$ futures market: An intraday analysis. In Carbon Markets Workshop: London School of Economics, 5 May 2009.

Blume, Marshall E., A. Craig Mackinlay, and Bruce Terker. (1989). Order Imbalances and Stock Price Movements on October 19 and 20, 1987. The Journal of Finance, 44(4), 827-848.

Bredin, Don, Stuart Hyde, and Cal Muckley. 2011. A Microstructure Analysis of the Carbon Finance Market. Dublin: University College Dublin Working Paper.

Brennan, M. J., and Avanidhar Subrahmanyam. (1998). The Determinants of Average Trade Size. The Journal of Business, 71(1), 1-25.

Brennan, Michael J., Narasimhan Jegadeesh, and Bhaskaran Swaminathan. (1993). Investment Analysis and the Adjustment of Stock Prices to Common Information. The Review of Financial Studies, 6(4), 799-824.

Brown, Stephen J., and Jerold B. Warner. (1985). Using daily stock returns : The case of event studies. Journal of Financial Economics, 14(1), 3-31.

Chang, Yuk Ying, Robert Faff, and Chuan-Yang Hwang. (2010). Liquidity and stock returns in Japan: New evidence. Pacific-Basin Finance Journal, 18(1), 90-115.

Charles, Amélie, Olivier Darné, and Jessica Fouilloux. (2013). Market efficiency in the European carbon markets. Energy Policy, 60(0), 785-792.

Chordia, Tarun, Richard Roll, and Avanidhar Subrahmanyam. (2001). Market Liquidity and Trading Activity. The Journal of Finance, 56(2), 501-530.

Chordia, Tarun, Richard Roll, and Avanidhar Subrahmanyam. (2005). Evidence on the speed of convergence to market efficiency. Journal of Financial Economics, 76(2), 271-292.

Chordia, Tarun, Richard Roll, and Avanidhar Subrahmanyam. (2008). Liquidity and market efficiency. Journal of Financial Economics, 87(2), 249-268.

Chordia, Tarun, and Avanidhar Subrahmanyam. (2004). Order imbalance and individual stock returns: Theory and evidence. Journal of Financial Economics, 72(3), 485-518. 
Chung, Dennis Y., and Karel Hrazdil. (2010a). Liquidity and Market Efficiency: A Large Sample Study. Journal of Banking \& Finance, 34(10), 2346-2357.

Chung, Dennis Y., and Karel Hrazdil. (2010b). Liquidity and market efficiency: Analysis of NASDAQ firms. Global Finance Journal, 21(3), 262-274.

Conrad, Christian, Daniel Rittler, and Waldemar Rotfuß. (2012). Modeling and explaining the dynamics of European Union Allowance prices at high-frequency. Energy Economics, 34(1), 316-326.

Cox, Don, R., and David R. Peterson. (1994). Stock Returns Following Large One-Day Declines: Evidence on Short-Term Reversals and Longer-Term Performance. The Journal of Finance, 49(1), 255-267.

Cushing, David, and Ananth Madhavan. (2000). Stock returns and trading at the close. Journal of Financial Markets, 3(1), 45-67.

Daskalakis, George. (2013). On the efficiency of the European carbon market: New evidence from Phase II. Energy Policy, 54(0), 369-375.

Daskalakis, George, Gbenga Ibikunle, and Ivan Diaz-Rainey. 2011. "The $\mathrm{CO}_{2}$ Trading Market in Europe: A Financial Perspective." In Financial Aspects in Energy: A European Perspective, edited by André Dorsman, Wim Westerman, Mehmet Baha Karan and Özgür Arslan, 51-67. Berlin Heidelberg: Springer.

Datar, Vinay T., Narayan Y. Naik, and Robert Radcliffe. (1998). Liquidity and stock returns: An alternative test. Journal of Financial Markets, 1(2), 203-219.

Ellerman, A. Denny, Frank J. Convery, and C. De Perthuis. 2010. "Price Carbon: The European Union Emissions Trading Scheme." In. New York: Cambridge University Press.

Epps, Thomas W. (1979). Comovements in Stock Prices in the Very Short Run. Journal of the American Statistical Association, 74(366), 291-298.

Fama, Eugene F. (1970). Efficient Capital Markets: A Review of Theory and Empirical Work. The Journal of Finance, 25(2), 383-417.

Flåm, Karoline Hægstad. 2007. A Multi-Level Analysis of the EU Linking Directive Process: The Controversial Connection between EU and Global Climate Policy. Oslo: Fridjof Nansen Institute Report.

Florackis, Chris, Andros Gregoriou, and Alexandros Kostakis. (2011). Trading frequency and asset pricing on the London Stock Exchange: Evidence from a new price impact ratio. Journal of Banking and Finance, 35(12), 3335-3350.

Frino, Alex, Jennifer Kruk, and Andrew Lepone. (2010). Liquidity and transaction costs in the European carbon futures market. Journal of Derivatives and Hedge Funds, 16(2), 100115.

Granger, C. W. J. (1969). Investigating Causal Relations by Econometric Models and Crossspectral Methods. Econometrica, 37(3), 424-438. 
Grossman, Sanford J., and Merton H. Miller. (1988). Liquidity and Market Structure. The Journal of Finance, 43(3), 617-633.

Grossman, Sanford J., and Joseph E. Stiglitz. (1980). On the Impossibility of Informationally Efficient Markets. The American Economic Review, 70(3), 393-408.

Hillmer, S. C., and P. L. Yu. (1979). The market speed of adjustment to new information. Journal of Financial Economics, 7(4), 321-345.

Huang, Roger D., and Hans R. Stoll. (1997). The Components of the Bid-Ask Spread: A General Approach. The Review of Financial Studies, 10(4), 995-1034.

Ibikunle, Gbenga, and Andros Gregoriou. 2011. "European Union Emissions Trading Scheme (EU-ETS) Futures Liquidity Effects: Evidence from the European Energy Exchange (EEX)." In In Proceedings of the 8th International Conference on Advances in Applied Financial Economics: 31/06/-02/07, 2011, 245-252. Samos Island: Research and Training Institute of East Aegean.

Ibikunle, Gbenga, Andros Gregoriou, and Naresh Pandit. (2013). Price Discovery and Trading After Hours: New Evidence from the World's Largest Carbon Exchange. International Journal of the Economics of Business, 20(3), 421-445.

Kalaitzoglou, Iordanis, and Boulis Maher Ibrahim. (2013). Does Order Flow in The European Carbon Futures Market Reveal Information? Journal of Financial Markets, 16(3), 604635.

Kellard, Neil, Paul Newbold, Tony Rayner, and Christine Ennew. (1999). The relative efficiency of commodity futures markets. Journal of Futures Markets, 19(4), 413-432.

Kossoy, Alexandre, and Phillipe Ambrosi. 2010. State and Trends of the Carbon Markets, 2010. Washington DC: The World Bank Report.

Krehbiel, Tim, and Lee C. Adkins. (1993). Cointegration tests of the unbiased expectations hypothesis in metals markets. Journal of Futures Markets, 13(7), 753-763.

Kyle, Albert S. (1985). Continuous Auctions and Insider Trading. Econometrica, 53(6), $1315-$ 1335.

Labatt, Sonia, and Rodney R. White. 2007. Carbon Finance: The Financial Implications of Climate Change. New Jersey: John Wiley \& Sons.

Linacre, Nicholas, Alexandre Kossoy, and Phillipe Ambrosi. 2011. State and Trends of the Carbon Market 2011. Washington DC: The World Bank Report.

Lo, AW, and AC MacKinlay. (1990). When are contrarian profits due to stock market overreaction? The Review of Financial Studies, 3(2), 175-205.

Mizrach, Bruce, and Yoichi Otsubo. (2014). The Market Microstructure of the European Climate Exchange. Journal of Banking \& Finance, 39(February), 107-116. 
Montagnoli, Alberto, and Frans P. de Vries. (2010). Carbon trading thickness and market efficiency. Energy Economics, 32(6), 1331-1336.

Newey, Whitney K., and Kenneth D. West. (1987). A Simple, Positive Semi-Definite, Heteroskedasticity and Autocorrelation Consistent Covariance Matrix. Econometrica, 55(3), 703-708.

O'Hara, Maureen. (2003). Presidential Address: Liquidity and Price Discovery. The Journal of Finance, 58(4), 1335-1354.

Pástor, Luboš, and Robert F Stambaugh. (2003). Liquidity Risk and Expected Stock Returns. The Journal of Political Economy, 111(3), 642-685.

Patell, James M., and Mark A. Wolfson. (1984). The intraday speed of adjustment of stock prices to earnings and dividend announcements. Journal of Financial Economics, 13(2), 223-252.

Peterson, Mark, and Erik Sirri. (2002). Order Submission Strategy and the Curious Case of Marketable Limit Orders. The Journal of Financial and Quantitative Analysis, 37(2), 221-241.

Ranson, Matthew, and Robert N. Stavins. 2012. Post-Durban Climate Policy Architecture Based on Linkage of Cap-and-Trade Systems. In National Bureau of Economic Research Working Paper Series. No. 18140.

Rotfuß, Waldemar. 2009. Intraday price formation and volatility in the European Union emissions trading scheme. Manheim: Centre for European Economic Research (ZEW) Working Paper

Stoll, Hans R. (1978). The Supply of Dealer Services in Securities Markets. The Journal of Finance, 33(4), 1133-1151.

Williams, E., and M. Kittel. (2004). Accession countries- Eastern promise: A market in Carbon-Preparing for the EU Emissions Trading Scheme. Environmental Finance, 1(4), 28-29. 
Figure 1

Market Efficiency measured by 15-minute return predictions with 15-minute lagged Euro Order Imbalance

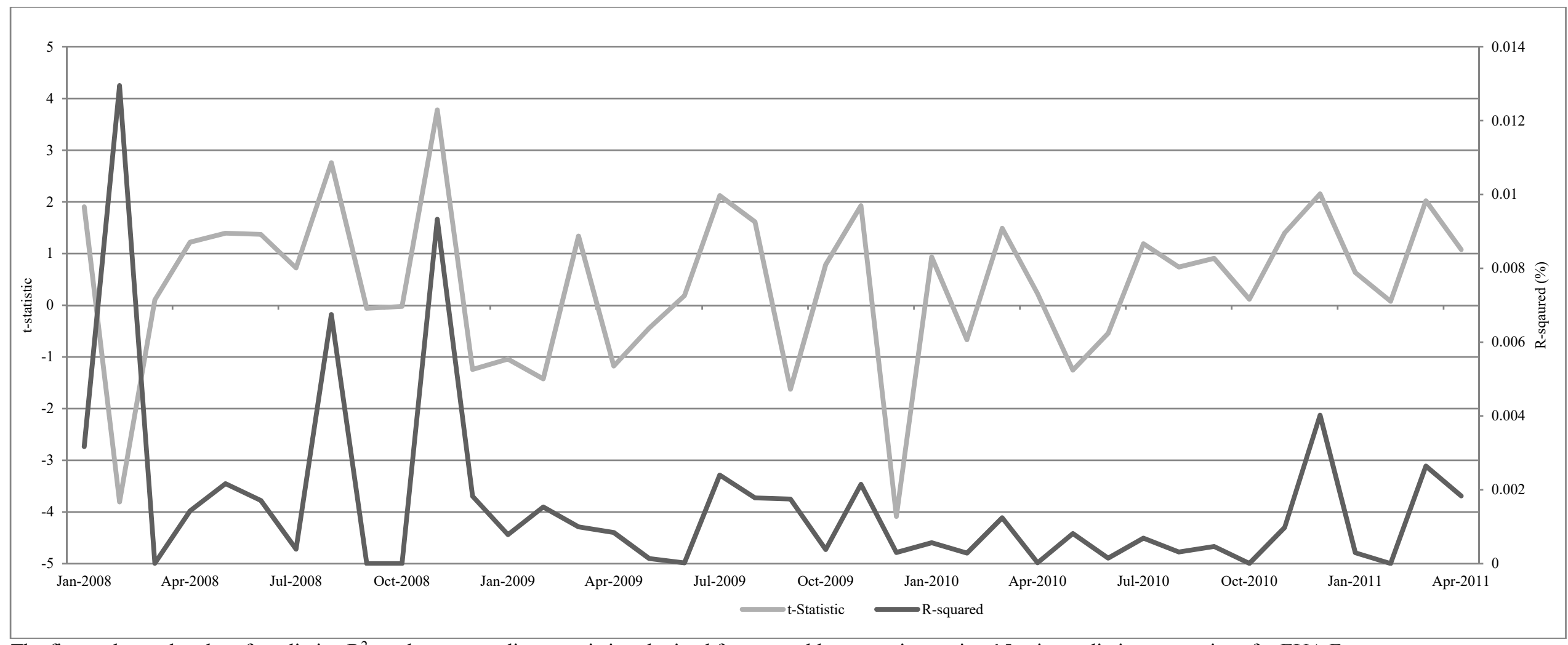

The figure shows the plot of predictive $\mathrm{R}^{2} \mathrm{~s}$ and corresponding t-statistics obtained from monthly regressions using 15-min predictive regressions for EUA Futures contracts on the ECX. OrderImbalance $\epsilon_{t-1}$ is given as the Euro value of buyer initiated trades less Euro value of seller initiated trades, then divided by the total Euro value of trades over the 15-minute interval, $t-1$. The Ret $_{t}$ computed for every 15 -minute interval using the last trade at every interval is the return at interval, $t$. The following regression is thus estimated:

$$
\text { ret }_{t}=\alpha+\beta \text { Order Imbalance } \text { I }_{t-1}+\varepsilon_{t}
$$

The data is for Phase II of the EU-ETS, and spans $2^{\text {nd }}$ January, 2008-29 ${ }^{\text {th }}$ April, 2011. The data includes December maturity EUA futures contracts traded during the period. The delineation of the contracts analysed for each year, based on trading activity constraints, is as follows: For Year 2008, the December 2008 , 2009 and 2010 maturities are used; for Year 2009, December 2009, 2010 and 2011 maturities are used; for Year 2010, December 2010, 2011 and 2012 maturities are used and the December 2011 and 2012 maturities are used for Year 2011. Note that none of the $\mathrm{R}^{2}$ values is actually zero. 
Figure 2

Daily Average Traded spread and Relative spread for ECX, 2008-2012

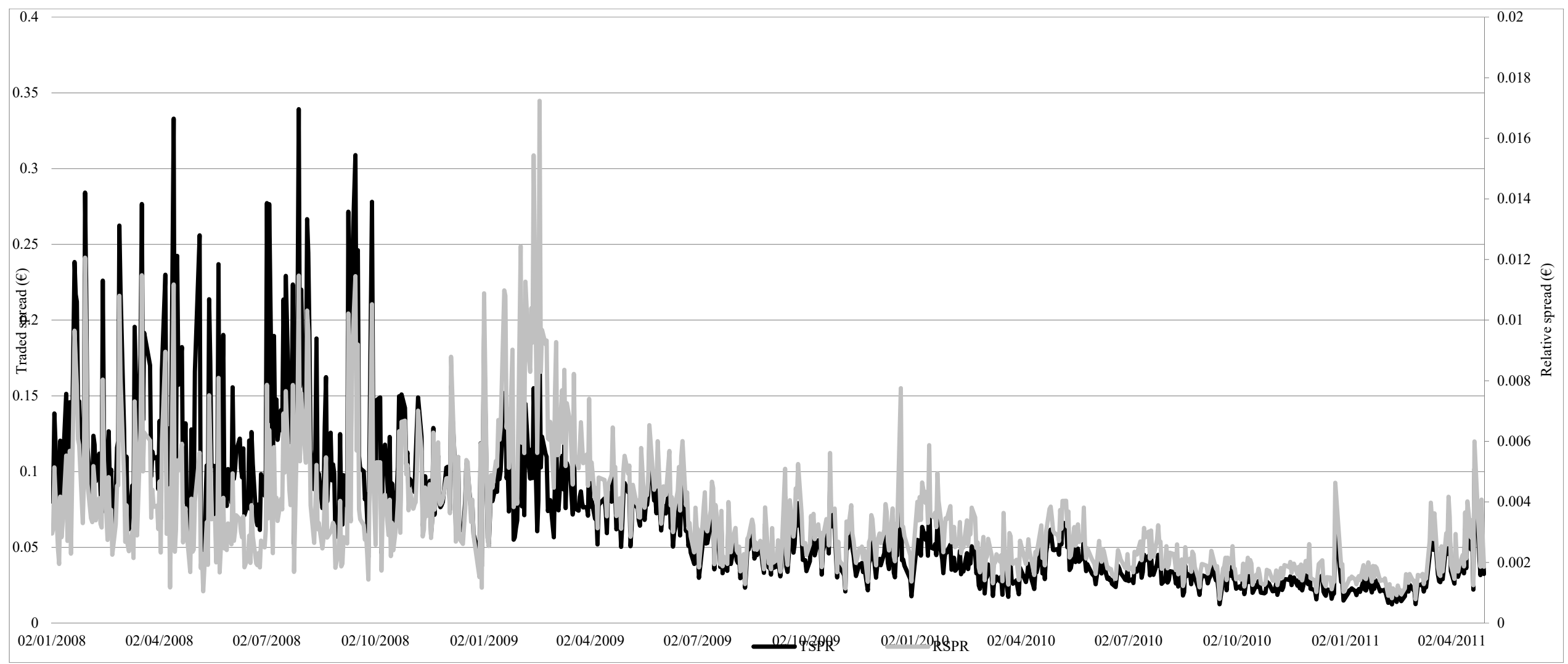

The Figure shows the plot of daily average of liquidity measures, traded spread and relative spread. Traded spread (TSPR) is the difference of best traded bid and ask prices for every 15-minute period; relative spread (RSPR) is defined as the best traded bid minus the best traded ask price, then divided by the average of the best traded bid and best ask over the same intervals. The spreads are averaged across the day for each instrument and cross-sectionally across all instruments. The data is for Phase II of the EU-ETS, and spans $2^{\text {nd }}$ January, 2008-29 ${ }^{\text {th }}$ April, 2011. The data includes December maturity EUA futures contracts traded during the period. The delineation of the contracts analysed for each year, based on trading activity constraints, is as follows: For Year 2008, the December 2008, 2009 and 2010 maturities are used; for Year 2009, December 2009, 2010 and 2011 maturities are used; for Year 2010, December 2010, 2011 and 2012 maturities are used and the December 2011 and 2012 maturities are used for Year 2011. 
Figure 3

Monthly Illiquidity/Price Impact Ratios

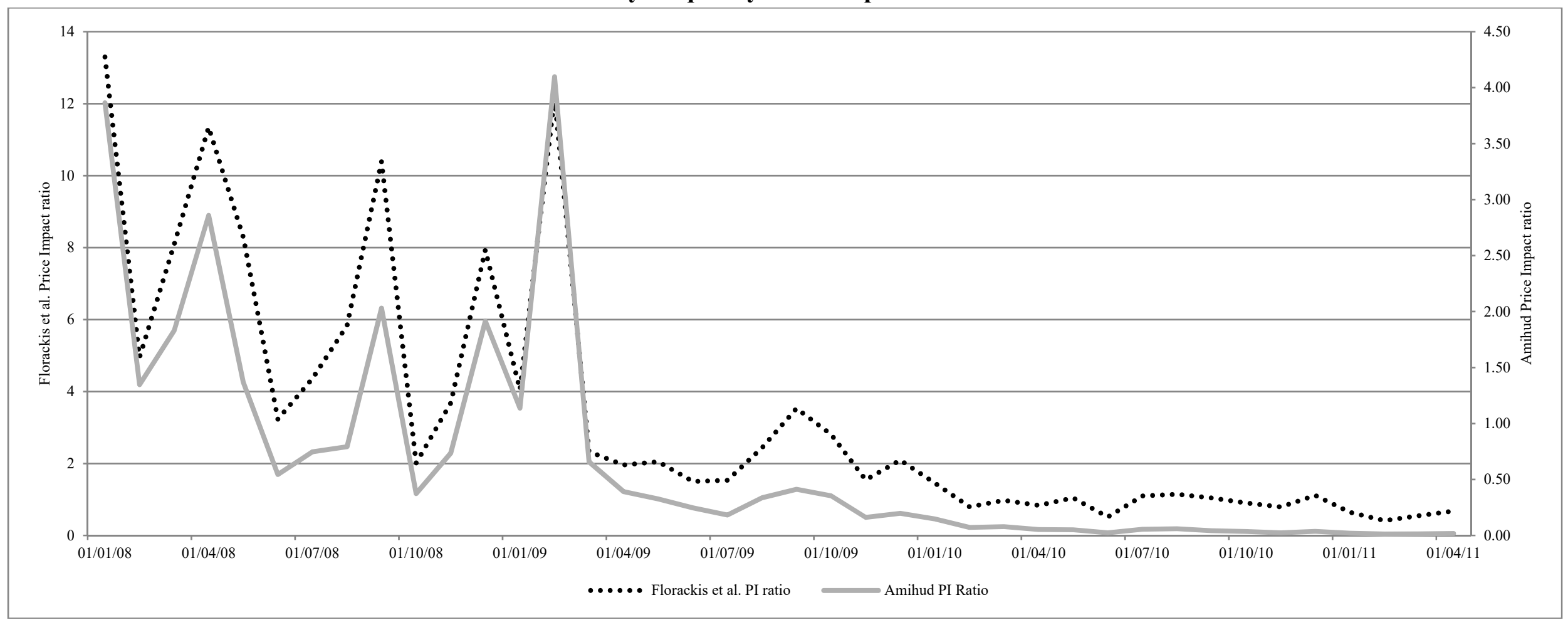

The figure shows the plot of monthly computed illiquidity ratios of Amihud (2002) and Florackis et al. (2011), respectively given below as (i) and (ii):

$$
\begin{aligned}
\text { Amihud }_{i t} & =\frac{1}{D_{i t}} \sum_{d=1}^{D_{i t}} \frac{\left|R_{i t d}\right|}{V_{i t d}} \\
\text { Florackis }_{i t} & =\frac{1}{D_{i t}} \sum_{d=1}^{D_{i t}} \frac{\left|R_{i t d}\right|}{T R_{i t d}}
\end{aligned}
$$

where $R_{i t d}, V_{i t d}$ and $T R_{i t d}$ are the return, euro volume and turnover ratio of EUA futures contract $i$ on day $d$ at month $t$ and $D_{i t}$ is the number of trading days in month $t$ for EUA futures $i$. The ratios are averaged cross-sectionally across all instruments. The data is for Phase II of the EU-ETS, and spans $2^{\text {nd }}$ January, 2008-29 $9^{\text {th }}$ April, 2011. The data includes December maturity EUA futures contracts traded on the ECX during the period. The delineation of the contracts analysed for each year, based on trading activity 
constraints, is as follows: For Year 2008, the December 2008, 2009 and 2010 maturities are used; for Year 2009, December 2009 , 2010 and 2011 maturities are used; for Year 2010, December 2010, 2011 and 2012 maturities are used and the December 2011 and 2012 maturities are used for Year 2011.

Table 1

Descriptive statistics for 15-minute liquidity and order imbalance proxies

\begin{tabular}{|c|c|c|c|c|c|}
\hline & & Traded Spread (€) & Relative Spread & $\mathrm{OIBQ}_{t}$ & $O I B \epsilon_{t}$ \\
\hline Entire sample & Mean & 69.00 & 3.45 & -18.90 & -28.70 \\
\hline $\mathrm{T}=847$ & Median & 54.00 & 2.88 & 0.24 & -21.40 \\
\hline $\mathrm{t}=58,836$ & Std. Dev. & 51.00 & 2.10 & 210.00 & 200.00 \\
\hline Phase II, Year I & Mean & 120.00 & 4.31 & -5.79 & -82.80 \\
\hline $\mathrm{T}=256$ & Median & 103.00 & 3.75 & 6.12 & -89.50 \\
\hline $\mathrm{t}=14,125$ & Std. Dev. & 58.00 & 2.17 & 330.00 & 250.00 \\
\hline Phase II, Year II & Mean & 65.00 & 4.26 & -30.20 & -12.50 \\
\hline $\mathrm{T}=254$ & Median & 60.00 & 3.70 & -14.10 & 14.80 \\
\hline $\mathrm{t}=18,550$ & Std. Dev. & 29.00 & 2.34 & 180.00 & 210.00 \\
\hline Phase II, Year III & Mean & 34.00 & 2.28 & -26.90 & -14.20 \\
\hline $\mathrm{T}=255$ & Median & 31.00 & 2.10 & -20.90 & -15.70 \\
\hline Phase II, Year IV & Mean & 31.00 & 1.92 & 20.4 & 2.77 \\
\hline $\mathrm{T}=82$ & Median & 25.00 & 1.55 & 1.90 & 7.77 \\
\hline $\mathrm{t}=4,922$ & Std. Dev. & 17.00 & 0.94 & 90.00 & 130.00 \\
\hline
\end{tabular}

This table shows descriptive statistics for liquidity and order imbalance measures computed from trading data for the ECX; all presented values are multiplied by a factor of $10^{3}$. Traded spread is the difference of best traded bid and ask prices for every 15-minute period; relative spread is defined as the best traded bid minus the best traded ask price, then divided by the average of the best traded bid and best ask over the same intervals. The spreads are averaged across the day for each instrument and cross-sectionally across all instruments. $O I B Q_{t}$ is the difference between the number buyer initiated trades and seller initiated trades, divided by total trades over every 15 -minute interval in a trading day. $O I B \epsilon_{t}$ is given as the Euro value of buyer initiated trades less Euro value of seller initiated trades, then divided by the total Euro value of trades over the same interval. $T$ is the total number of days during a trading period/year; $t$ is the aggregate number 15-minute intervals for all the instruments. The data is for Phase II of the EU-ETS, and spans $2^{\text {nd }}$ January, 2008-29 $9^{\text {th }}$ April, 2011. The data includes December maturity EUA futures contracts traded during the period. The delineation of the contracts analysed for each 
year, based on trading activity constraints, is as follows: For Year 2008, the December 2008, 2009 and 2010 maturities are used; for Year 2009 , December 2009, 2010 and 2011 maturities are used; for Year 2010, December 2010, 2011 and 2012 maturities are used and the December 2011 and 2012 maturities are used for Year 2011. 
Table 2

Correlations for 15-minute trading intervals on the ECX

\begin{tabular}{|c|c|c|c|}
\hline & & \multirow{2}{*}{\multicolumn{2}{|c|}{ Return $O I B_{O t-1}$}} \\
\hline & & & \\
\hline Whole Sample (2008-2011) & $O I B Q_{t-1}$ & 0.01 & \\
\hline $\mathrm{t}=58,836$ & $O I B \epsilon_{t-1}$ & 0.00 & $0.53 * * *$ \\
\hline Phase II, Year I & $O I B Q_{t-1}$ & $0.02 *$ & \\
\hline $\mathrm{t}=14,125$ & $O I B \epsilon_{t-1}$ & $0.02 *$ & $0.39 * * *$ \\
\hline Phase II, Year II & $O I B Q_{t-1}$ & $-0.01 *$ & \\
\hline $\mathrm{t}=18,550$ & $O I B €_{t-1}$ & $-0.01 *$ & $0.80 * * *$ \\
\hline Phase II, Year III & $O I B Q_{t-1}$ & $0.02 * *$ & \\
\hline $\mathrm{t}=21,239$ & $O I B \epsilon_{t-1}$ & 0.01 & $0.64 * * *$ \\
\hline Phase II, Year IV & $O I B Q_{t-1}$ & 0.02 & \\
\hline $\mathrm{t}=4,922$ & $O I B \epsilon_{t-1}$ & $0.03 * *$ & $0.55 * * *$ \\
\hline
\end{tabular}

The table shows correlations values for three variables. $O I B Q_{t}$ is the difference between number buyer initiated trades and seller initiated trades, divided by total trades over every 15 -minute interval in a trading day. OIB $\epsilon_{t}$ is given as the Euro value of buyer initiated trades less Euro value of seller initiated trades, then divided by the total Euro value of trades over the same interval. The return is computed for every 15-minute interval using the last trade at every interval. $t$ is the aggregate number of 15 minute intervals for all the instruments. The data is for Phase II of the EU-ETS, and spans $2^{\text {nd }}$ January, 2008-29 $9^{\text {th }}$ April, 2011. The data includes December maturity EUA futures contracts traded during the period. $* * *, * *$ and $*$ represents statistical significance at $1 \%, 5 \%$ and $10 \%$ levels respectively. The delineation of the contracts analysed for each year, based on trading activity constraints, is as follows: For Year 2008, the December 2008, 2009 and 2010 maturities are used; for Year 2009, December 2009, 2010 and 2011 maturities are used; for Year 2010, December 2010, 2011 and 2012 maturities are used and the December 2011 and 2012 maturities are used for Year 2011. 
Table 3

Predictive regressions of 15-min returns on lagged Order Imbalance

\section{Panel A}

\begin{tabular}{|c|c|c|c|}
\hline \multicolumn{4}{|c|}{ Dependent Variable: Ret $_{t}$} \\
\hline Whole Sample (2008-2011) & Coefficient & t-statistic & \\
\hline Intercept & 0.35 & 0.13 & \\
\hline$O I B Q_{t-1}$ & 18.10 & 1.46 & \\
\hline R-squared & & & 3.60 \\
\hline \multicolumn{4}{|l|}{ Phase II, Year I } \\
\hline Intercept & -5.09 & -0.84 & \\
\hline$O I B Q_{t-1}$ & $32.50^{*}$ & 1.77 & \\
\hline R-squared & & & 25.30 \\
\hline \multicolumn{4}{|l|}{ Phase II, Year II } \\
\hline Intercept & -1.23 & -0.19 & \\
\hline$O I B Q_{t-1}$ & 0.36 & 1.00 & \\
\hline R-squared & & & 24.40 \\
\hline \multicolumn{4}{|l|}{ Phase II, Year III } \\
\hline Intercept & 2.69 & 1.19 & \\
\hline$O I B Q_{t-1}$ & $36.80 * *$ & 2.32 & \\
\hline R-squared & & & 22.20 \\
\hline \multicolumn{4}{|l|}{ Phase II, Year IV } \\
\hline Intercept & $7.54 * *$ & 2.08 & \\
\hline$O I B Q_{t-1}$ & $44.1 * *$ & 2.10 & \\
\hline R-squared & & & 5.40 \\
\hline
\end{tabular}




\section{Panel B}

\begin{tabular}{|c|c|c|c|}
\hline \multicolumn{4}{|c|}{ Dependent Variable: Ret $_{t}$} \\
\hline Whole Sample (2008-2011) & Coefficient & t-Statistic & \\
\hline Intercept & -0.17 & -0.07 & \\
\hline$O I B €_{t-1}$ & 5.90 & 0.46 & \\
\hline R-squared & & & 0.40 \\
\hline \multicolumn{4}{|l|}{ Phase II, Year I } \\
\hline Intercept & $-8.28 * *$ & -2.34 & \\
\hline$O I B €_{t-1}$ & $0.58 * *$ & 2.07 & \\
\hline R-squared & & & 22.90 \\
\hline \multicolumn{4}{|l|}{ Phase II, Year II } \\
\hline Intercept & -0.84 & -0.14 & \\
\hline$O I B €_{t-1}$ & $54.7^{*}$ & 1.84 & \\
\hline R-squared & & & 18.30 \\
\hline \multicolumn{4}{|l|}{ Phase II, Year III } \\
\hline Intercept & 1.96 & 0.88 & \\
\hline$O I B €_{t-1}$ & 0.18 & 1.36 & \\
\hline R-squared & & & 8.70 \\
\hline \multicolumn{4}{|l|}{ Phase II, Year IV } \\
\hline Intercept & -1.67 & -0.26 & \\
\hline$O I B €_{t-1}$ & $0.44 *$ & 1.80 & \\
\hline R-squared & & & 8.68 \\
\hline
\end{tabular}

Panel A shows results for 15-min predictive regressions for EUA Futures contracts on the ECX. $O I B Q_{t-1}$ is the difference between number buyer initiated trades and seller initiated trades, divided by total trades over the 15-minute interval, $t$ 1 . The Ret $_{t}$, computed for every 15-minute interval using the last trade at every interval is the return at interval, $t$. Panel $\mathrm{B}$ shows results for 15-min predictive regressions for EUA Futures contracts on the ECX. OIB€ $\epsilon_{t-1}$ is given as the Euro value of buyer initiated trades less Euro value of seller initiated trades, then divided by the total Euro value of trades over the 15-minute interval, $t-1$. The Ret $_{t}$, computed for every 15-minute interval, using the last trade at every interval, is the return at interval, $t$. Specifically, the following regression is estimated using least squares with Newey and West (1987) HAC:

$$
\text { ret }_{t}=\alpha+\beta \text { Order Im } \text { balance }_{t-1}+\varepsilon_{t}
$$

All coefficient and $\mathrm{R}^{2}$ values are multiplied by a factor of $10^{5} . * * *, * *$ and * represents statistical significance at $1 \%, 5 \%$ and $10 \%$ levels respectively. The data used is for Phase II of the EU-ETS, and spans $2^{\text {nd }}$ January $2008-29^{\text {th }}$ April 2011. The data includes December maturity EUA futures contracts traded during the period. The delineation of the contracts analysed for each year, based on trading activity constraints, is as follows: For Year 2008, the December 2008, 2009 and 2010 maturities are used; for Year 2009, December 2009, 2010 and 2011 maturities are used; for Year 2010, December 2010, 2011 and 2012 maturities are used and the December 2011 and 2012 maturities are used for Year 2011. 
Table 4

Distribution of liquid and illiquid days on the ECX (2008-2011)

\begin{tabular}{llcc} 
& & Relative Spread on liquid days & Relative Spread on illiquid days \\
\cline { 3 - 4 } Phase II, Year I & Mean & 4.31 & 4.37 \\
& Median & 3.74 & 4.45 \\
& Std. Dev. & 2.22 & 0.85 \\
& Sample days, T & 223 & 33 \\
\cline { 3 - 4 } Phase II, Year II & Mean & 4.17 & 4.98 \\
& Median & 3.61 & 4.51 \\
& Std. Dev. & 2.36 & 2.08 \\
& Sample days, T & 225 & 29 \\
\cline { 3 - 4 } Phase II, Year III & & & 2.22 \\
& Mean & 2.29 & 2.10 \\
& Median & 2.09 & 0.55 \\
& Std. Dev. & 8.24 & 25 \\
& Sample days, T & 230 & 1.65 \\
\cline { 3 - 4 } & & 1.94 & 1.42 \\
\hline Phase II, Year IV & Mean & 1.59 & 0.52 \\
& Median & 0.97 & 7 \\
& Std. Dev. & 75 & \\
& Sample days, T & & \\
\cline { 3 - 4 }
\end{tabular}

The table shows distribution of liquid and illiquid days on the ECX. The daily relative spread, measure of liquidity is computed using December maturity EUA futures contracts. The relative spread is defined as the best traded bid minus the best traded ask price scaled by the average of the best traded bid and ask prices over 15-minute intervals, then averaged for each trading day. For every day when the daily relative spread is at least one standard deviation above the mean relative spread for the surrounding period over ($30,+30)$, we define the day as illiquid and when it is not, liquid. All spread estimates are multiplied by a factor of $10^{3}$.The data is for Phase II of the EU-ETS, and spans $2^{\text {nd }}$ January 2008-29 $9^{\text {th }}$ April 2011. The data includes December maturity EUA futures contracts traded during the period. The delineation of the contracts analysed for each year, based on trading activity constraints, is as follows: For Year 2008, the December 2008, 2009 and 2010 maturities are used; for Year 2009 , December 2009, 2010 and 2011 maturities are used; for Year 2010, December 2010, 2011 and 2012 maturities are used and the December 2011 and 2012 maturities are used for Year 2011. 
Table 5

Predictive regressions of 15-minute returns on lagged $O I B €_{t}$ and lagged $O I B \epsilon_{t}$ interacted with an illiquidity dummy

\begin{tabular}{|c|c|c|c|c|c|}
\hline & & Coefficient & t-statistic & Probability & \\
\hline Phase II, Year I & Intercept & -0.09 & -0.14 & 0.89 & \multirow[b]{4}{*}{38.00} \\
\hline \multirow[t]{3}{*}{$\mathrm{t}=13,869$} & $O I B €_{t-1} *$ ILD & $33.40 * * *$ & 4.05 & 0.00 & \\
\hline & $O I B €_{t-1}$ & 1.62 & 0.64 & 0.52 & \\
\hline & R-squared & & & & \\
\hline Phase II, Year II & Intercept & -0.07 & -0.12 & 0.91 & \multirow[b]{4}{*}{13.90} \\
\hline \multirow[t]{3}{*}{$\mathrm{t}=18,296$} & $O I B €_{t-1} *$ ILD & $33.10 * * *$ & 3.80 & 0.00 & \\
\hline & $O I B €_{t-1}$ & 3.08 & 0.98 & 0.33 & \\
\hline & R-squared & & & & \\
\hline Phase II, Year III & Intercept & 0.20 & 0.89 & 0.37 & \multirow[b]{4}{*}{1.45} \\
\hline \multirow[t]{3}{*}{$\mathrm{t}=20,984$} & $O I B €_{t-1} * I L D$ & 4.38 & 1.12 & 0.26 & \\
\hline & $O I B \epsilon_{t-1}$ & 1.23 & 0.86 & 0.39 & \\
\hline & R-squared & & & & \\
\hline Phase II, Year IV & Intercept & $0.82 * *$ & 2.31 & 0.02 & \multirow[b]{4}{*}{4.51} \\
\hline \multirow[t]{3}{*}{$\mathrm{t}=4,840$} & $O I B €_{t-1} *$ ILD & $20.70 * *$ & 2.23 & 0.03 & \\
\hline & $O I B €_{t-1}$ & 1.91 & 0.64 & 0.52 & \\
\hline & R-squared & & & & \\
\hline
\end{tabular}

The table shows results for 15-min predictive regressions for EUA Futures contracts on the ECX. OIB $\epsilon_{t-1}$ is given as the Euro value of buyer initiated trades less Euro value of seller initiated trades, then divided by the total Euro value of trades over the 15-minute interval, $t_{-I}$. The Ret $t_{t}$, is computed for every 15 -minute interval using the last trade at every interval is the return at interval, $t$. The dummy ILD is 1.0 for every day when the daily relative spread is at least one standard deviation above the mean relative spread for the surrounding period over $(-30,+30)$ and 0 otherwise. Specifically, the following regression is estimated using least squares with Newey and West (1987) HAC:

$$
\text { ret }_{t}=\alpha+\beta_{1} \text { Order Imbalance }_{t-1}+\beta_{2} \text { Order Imbalance }_{t-1} * I L D+\varepsilon_{t}
$$

All coefficient and $\mathrm{R}^{2}$ values are multiplied by a factor of $10^{4} . * * *, * *$ and * represents statistical significance at $1 \%, 5 \%$ and $10 \%$ levels respectively. The data is for Phase II of the EU-ETS, and spans $2^{\text {nd }}$ January, 2008-29 $9^{\text {th }}$ April, 2011. The data includes December maturity EUA futures contracts traded during the period. The delineation of the contracts analysed for each year, based on trading activity constraints, is as follows: For Year 2008, the December 2008, 2009 and 2010 maturities are used; for Year 2009 , 
December 2009, 2010 and 2011 maturities are used; for Year 2010, December 2010, 2011 and 2012 maturities are used and the December 2011 and 2012 maturities are used for Year 2011.

Table 6

Liquidity and market efficiency dynamics: Granger causality analysis

Panel A. Daily contract-specific (year-dependent) liquidity and market efficiency dynamics

\begin{tabular}{|c|c|c|c|}
\hline & & $\begin{array}{c}\text { Order Imbalance does not cause } \\
\text { Relative Spread }\end{array}$ & $\begin{array}{c}\text { Relative Spread does not cause Order } \\
\text { Imbalance }\end{array}$ \\
\hline \multirow[t]{3}{*}{ Phase II, Year I } & Dec-2008 Futures & 1.48 & $2.40 * * *$ \\
\hline & Dec-2009 Futures & 0.97 & $2.93 * * *$ \\
\hline & Dec-2010 Futures & 0.78 & $2.04 *$ \\
\hline \multirow[t]{3}{*}{ Phase II, Year II } & Dec-2009 Futures & $1.98 * *$ & $2.63 * * *$ \\
\hline & Dec-2010 Futures & $5.24 * * *$ & $2.77 * * *$ \\
\hline & Dec-2011 Futures & 1.56 & $2.88 * * *$ \\
\hline \multirow[t]{3}{*}{ Phase II, Year III } & Dec-2010 Futures & 1.06 & $2.44 * *$ \\
\hline & Dec-2011 Futures & $1.70 * *$ & $1.71 * *$ \\
\hline & Dec-2012 Futures & $4.69 * * *$ & $2.54 * *$ \\
\hline \multirow[t]{2}{*}{ Phase II, Year IV } & Dec-2011 Futures & 0.19 & 0.14 \\
\hline & Dec-2012 Futures & 0.30 & 0.98 \\
\hline
\end{tabular}


Panel B. Daily contract-specific liquidity and market efficiency dynamics: Granger causality analysis

\begin{tabular}{ccc}
\cline { 2 - 3 } & $\begin{array}{c}\text { Order Imbalance does not cause } \\
\text { Relative Spread }\end{array}$ & $\begin{array}{c}\text { Relative Spread does not cause Order } \\
\text { Imbalance }\end{array}$ \\
\hline Dec-2008 Futures & 1.48 & $2.40^{* * *}$ \\
Dec-2009 Futures & 1.50 & $4.76^{* * *}$ \\
Dec-2010 Futures & $1.68^{*}$ & $4.45^{* * *}$ \\
Dec-2011 Futures & 0.65 & $3.39^{* * *}$ \\
Dec-2012 Futures & $2.83^{* * *}$ & $2.26^{* * *}$ \\
\hline
\end{tabular}

The Table shows results for the Granger (1969) causality analysis. A model of the following form:

$$
\begin{aligned}
& \varphi_{t}=\alpha_{0}+\alpha_{1} \varphi_{t-1}+\ldots+\alpha_{l} \varphi_{l-1}+\beta_{1} \delta_{t-1}+\ldots+\beta_{l} \delta_{l-1}+\varepsilon_{t} \\
& \delta_{t}=\alpha_{0}+\alpha_{1} \delta_{t-1}+\ldots+\alpha_{l} \delta_{l-1}+\beta_{1} \varphi_{t-1}+\ldots+\beta_{l} \varphi_{l-1}+\mu_{t}
\end{aligned}
$$

is estimated for the likely pairings of $(\delta, \varphi)$ series in the set. $\delta$ denotes the daily mean of the 15 -minute Euro order imbalance measure, $\varphi$ is the daily relative spread liquidity proxy and $l$ is the lag length. F-statistics in the table are the Wald statistics for the joint hypothesis:

$$
\beta_{1}=\beta_{2}=\ldots=\beta_{l}=0
$$

for each of the bivariate equations. The null tested is that $\delta$ does not Granger-cause $\varphi$ in the top equation and that $\varphi$ does not Granger-cause $\delta$ in the bottom equation. Panel A shows contract-specific (year/period-dependent) results, while Panel B shows contract-specific results with no breaks. ***, ** and * represents statistical significance at $1 \%$, $5 \%$ and $10 \%$ levels respectively. The data is for Phase II of the EU-ETS, and spans $2^{\text {nd }}$ January, 2008-29 $9^{\text {th }}$ April, 2011. The variables are computed from December maturity EUA futures contracts traded during the period. The delineation of the contracts analysed for each year, based on trading activity constraints, is as follows: For Year 2008, the December 2008, 2009 and 2010 maturities are used; for Year 2009, December 2009, 2010 and 2011 maturities are used; for Year 2010, December 2010, 2011 and 2012 maturities are used and the December 2011 and 2012 maturities are used for Year 2011. 
Table 7

\section{Daily variance ratios for EUA futures contracts across trading periods}

\begin{tabular}{|c|c|c|c|c|}
\hline & Year I & Year II & Year III & Year IV \\
\hline Dec-2008 & 2.18 & & & \\
\hline Dec-2009 & 9.47 & $3.46 * * *$ & & \\
\hline Dec-2010 & 16.61 & $3.13 * * *$ & $1.08 * * *$ & \\
\hline Dec-2011 & & 5.68 & $1.96 * * *$ & $1.43 *$ \\
\hline Dec-2012 & & & 2.44 & $1.37 * *$ \\
\hline Value weighted overall & 3.74 & 3.22 & 1.39 & 1.42 \\
\hline
\end{tabular}

This table shows contract-specific ratio of 15-minute return variance to open-to-close return variance, scaled by the number of 15 -minute intervals in a trading day on the ECX.

The final row in the table is the trading value-weighted aggregate variance ratio per period. Data is as defined as Table $1 . * * *, * *$ and $*$ denote values which are significantly different from the previous compliance year's value at $1 \%, 5 \%$ and $10 \%$ levels respectively. The data used is for Phase II of the EU-ETS, and spans $2^{\text {nd }}$ January, $2008-29^{\text {th }}$ April, 2011. The variables are computed from December maturity EUA futures contracts traded during the period. The delineation of the contracts analysed for each year, based on trading activity constraints, is as follows: For Year 2008, the December 2008, 2009 and 2010 maturities are used; for Year 2009, December 2009, 2010 and 2011 maturities are used; for Year 2010, December 2010, 2011 and 2012 maturities are used and the December 2011 and 2012 maturities are used for Year 2011. 